\title{
$\mathfrak{I} \mathfrak{n} \mathfrak{h} \mathfrak{a} \mathfrak{l} \mathfrak{t}$
}

\section{Erfter abidnitt.}

Uleberfidt ber Staatoverbaltniffe beim Beginn bes felb.

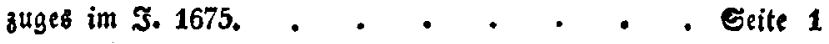

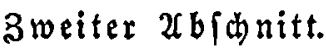

ueber bie Eandesberdaffengeit bes Iheiles ber Mark 5 ran: benburg, in weldem ber felogug von 1675 gefübrt wurbe.

Dritter $\mathfrak{W} \mathfrak{b}$ fdnitt.

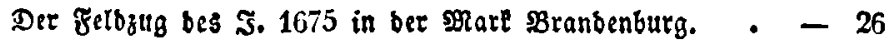
Beilagen. . . . . . . . . . -81 
